تصميم الألعاب التعليمية ثلاثية الابعاد المدعمة بتقنية الواقع المعزز

\title{
3d Educational Games Supported By Augmented Reality
}

$$
\begin{aligned}
& \text { (تعليم مناسلك الحج كتطبيق عملي) } \\
& \text { ابر اهيم حسن } \\
& \text { مدرس - بقسم التصميمات } \\
& \text { كلية القنون الجميلة - جامعة الإسكندرية } \\
& \text { الإسكندرية - مصر الجملة جامعة الإن }
\end{aligned}
$$

\section{Ibrahim Hassan}

Lecturer Faculty of fine Arts, Department of Graphic design

Alexandria University, Egypt

Ibrahim_hassan@alexu.edu.eg

$$
\begin{aligned}
& \text { عاطف زكي أحمد كرشة } \\
& \text { مدرس - بقسم التصميمات } \\
& \text { كلية الفنون الجميلة - جامعة الإسكندرية }
\end{aligned}
$$

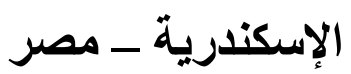

$$
\begin{aligned}
& \text { Atef Zaki }
\end{aligned}
$$

Lecturer Faculty of fine Arts, Department of Graphic design

Alexandria University, Egypt

Atef.zaki@alexu.edu.eg 
ان التعليم وتطوير المهار ات الفكرية للأطفال هو التوظيف الأهم لمجال الاتصـال البصري و الذي تسـار ع نموه بشكل كبير

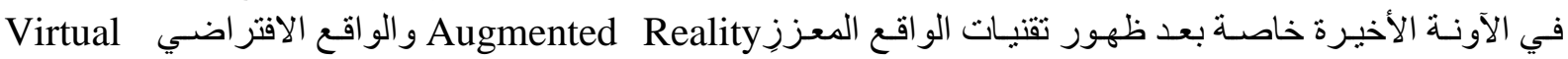

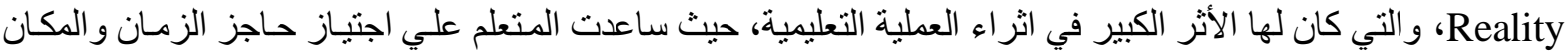

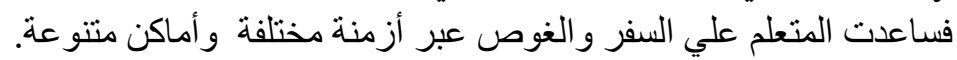

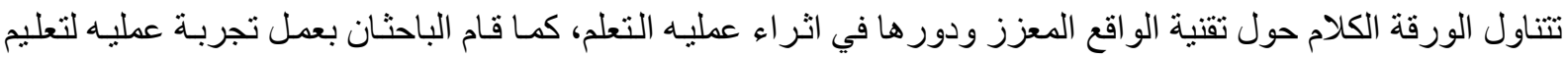

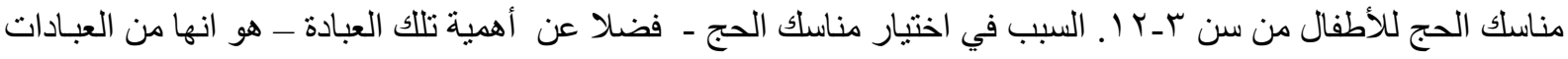

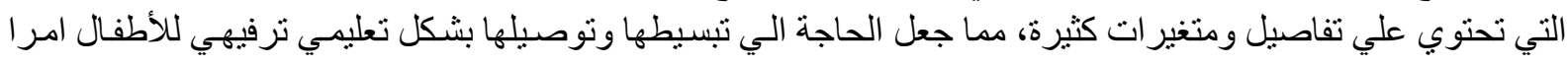
حيويا. ان تصميم اللعبة مر بعدة مر احل تبدأ من المخططات و الخر ائط الذهنية و الانفوجر افيك، مرور ا بتصميم و اجهة المستخدم

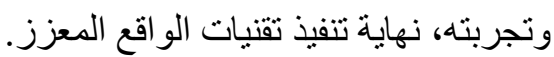

\begin{abstract}
:
Education and the development of children's intellectual skills is the most important employment for the field of visual communication, which has accelerated significantly in recent times, especially after the emergence of Augmented Reality and Virtual Reality technologies, which had a significant impact on enriching the educational process, as it helped the learner to cross the barrier of time and space. She helped the learner to travel and dive through different times and places. The paper discusses augmented reality technology and its role in enriching the learning process. The researchers also conducted a practical experiment to teach the rituals of Hajj for children aged 3-6. The reason for choosing the rituals of Hajj in addition to the importance of that worship - is that it is one of the acts of worship that contains many details and variables, which made the need to simplify and communicate it in an educational and entertaining way for children a vital matter. The design of the game has gone through several stages, starting with plans, mental maps and infographics, through the design and experience of the user interface, and the end of the implementation of augmented reality techniques.
\end{abstract}

$$
\text { الكلمات المفتاحية: الو اقع المعزز، التعليم الترفيهي، التعليم الرقمي. }
$$

Keywords: augmented reality, entertainment education, digital education.

$$
\begin{aligned}
& \text { هدف البحث: } \\
& \text { الجمع بين الوسائط المادية و الرقمية لتبسيط تعلم مناسك الحج للأطفال من سن بـآ سنوات. }
\end{aligned}
$$

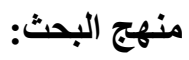

$$
\begin{aligned}
& \text { من خلال تجربة الباحث العملية يعتمد الباحثان علي المنهج الوصفي والتجريبي. }
\end{aligned}
$$




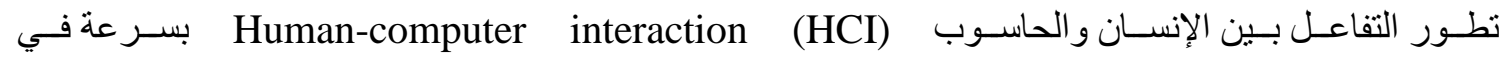

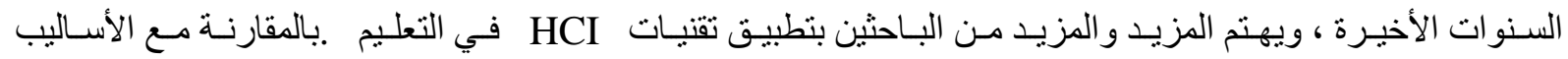

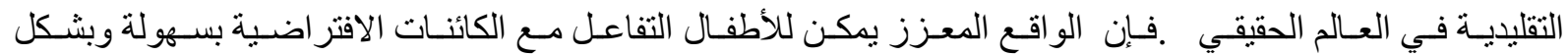

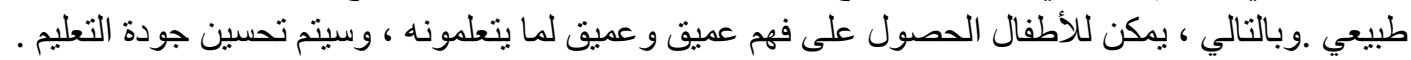

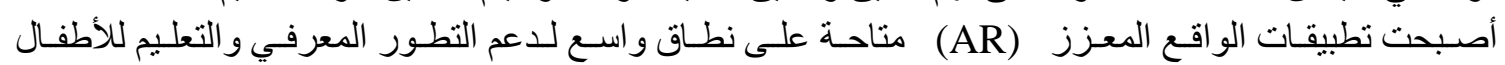

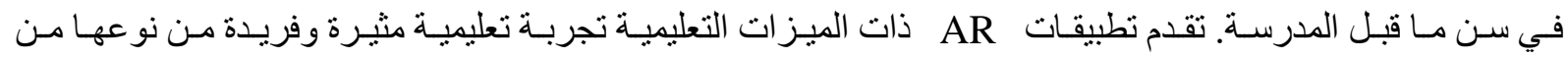

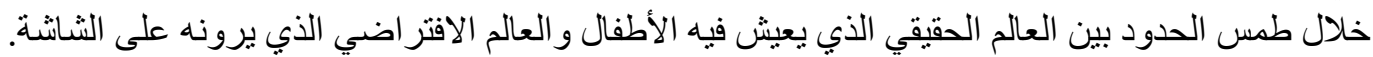

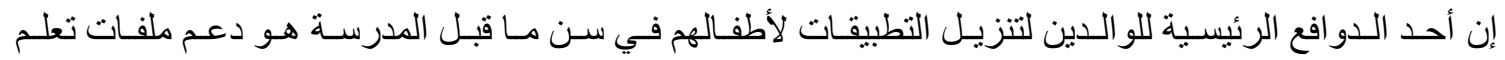

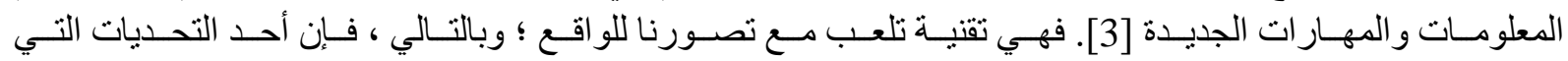

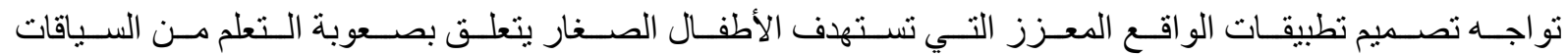

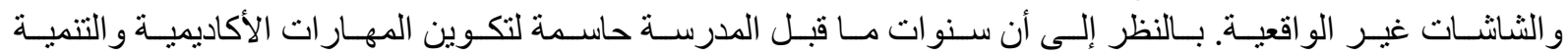

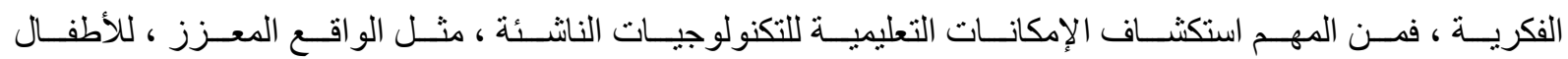

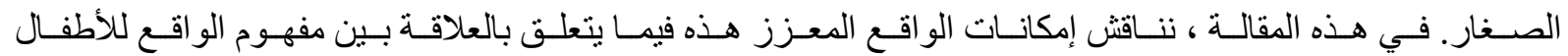
وتعلمهح .

\section{فاعلية الواقع المعزز}

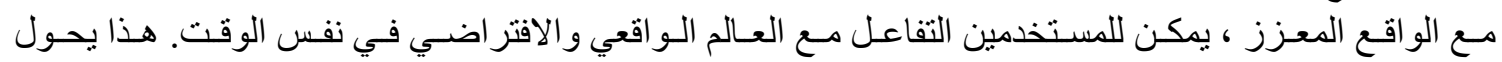

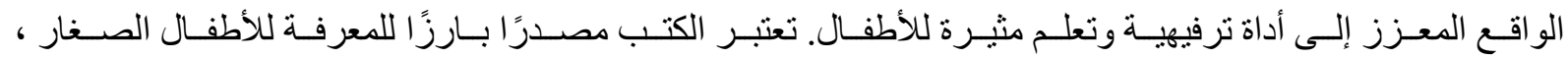

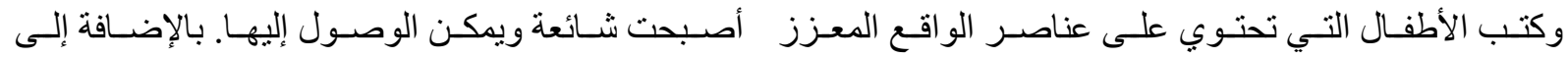

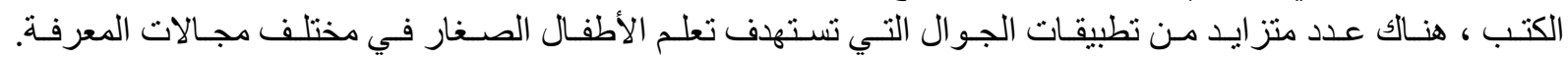

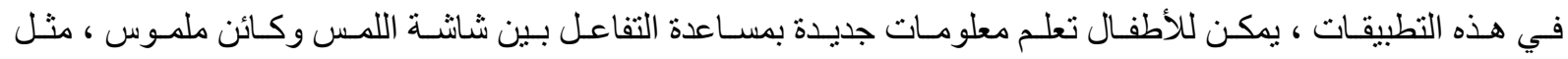

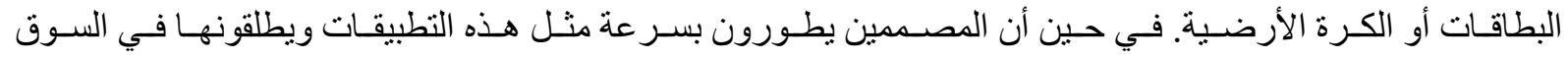

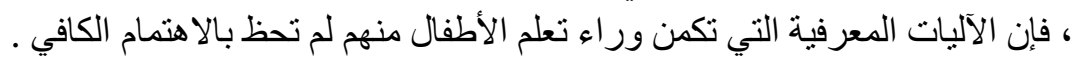

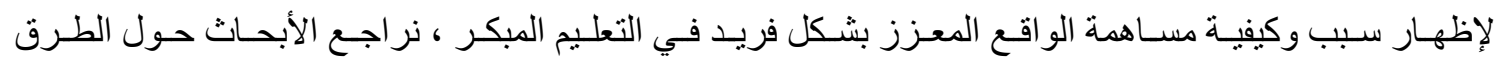

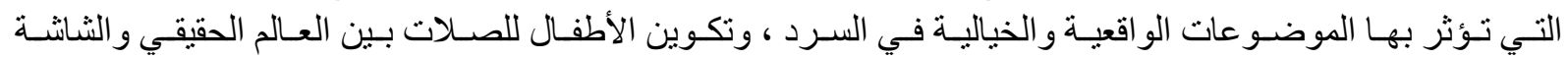

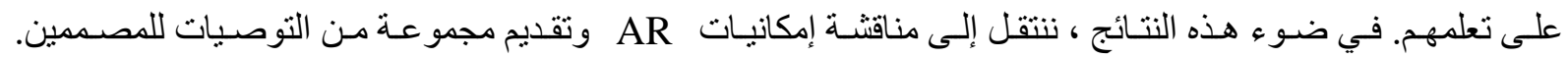

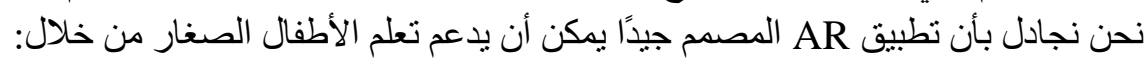

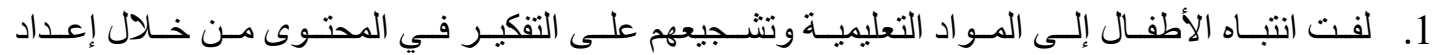
مشهد غبر تقلبدي للتعلم.

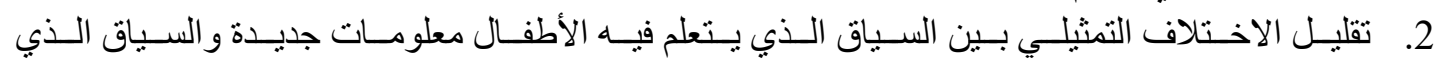
يحتاجون إليه لتطبيق ما تعلموه. 


\section{الواقع المعزز كوسيلة تعليمية ترفيهية}

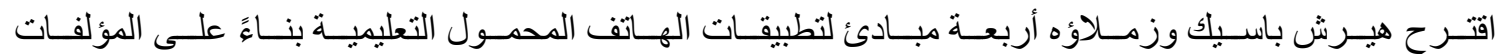

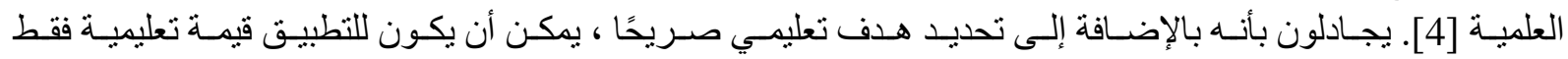

$$
\begin{aligned}
& \text { 1. يمكّن الأطفال من المشاركة بنشاط في العملية ، ولئة }
\end{aligned}
$$

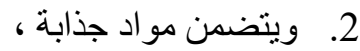

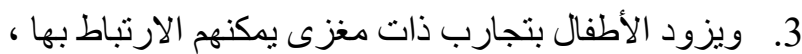

$$
\begin{aligned}
& \text { 4. ويوفر بيئة التفاعل الاجتماعي كله في نفس الوقت الأت }
\end{aligned}
$$

\section{تسهيل التعلم من خلال الربط بين الواقع الإفتراضي والواقع الفعلي}

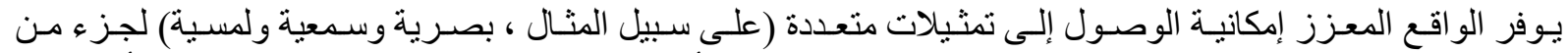

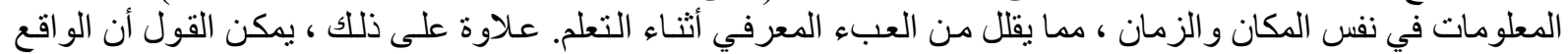

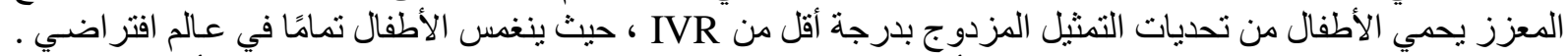

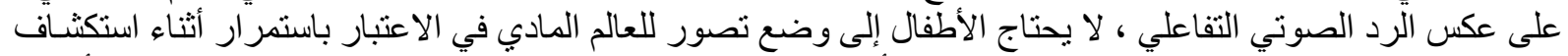

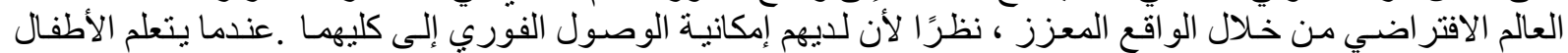

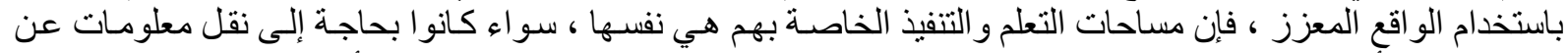

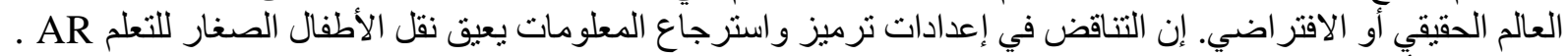

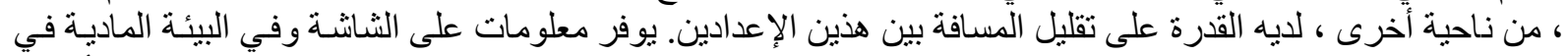

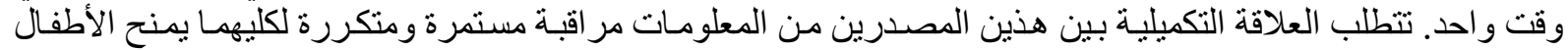

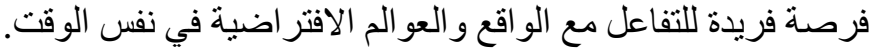

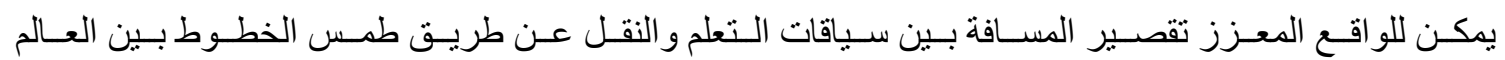

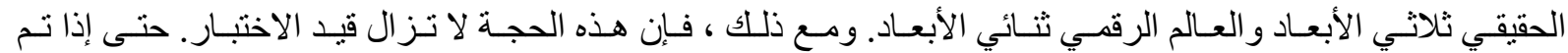

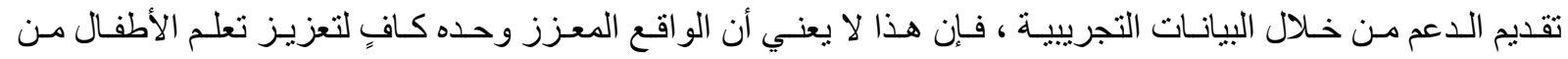

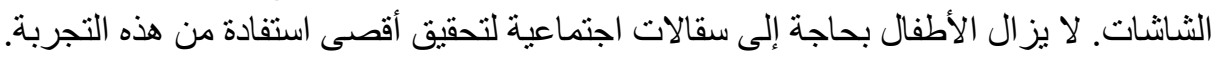

\section{قصة الحج كتجربة تعليمية}

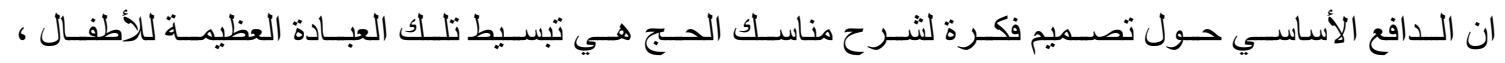

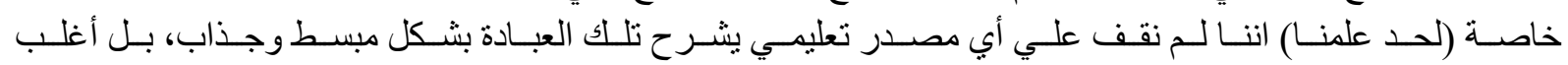

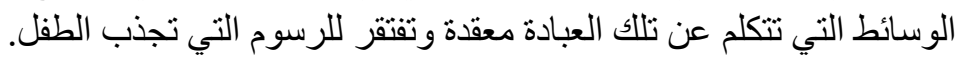

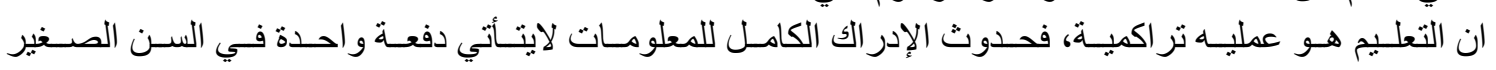

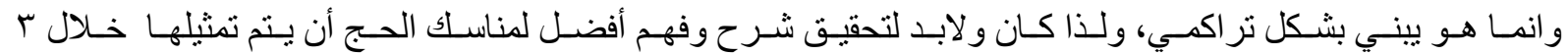




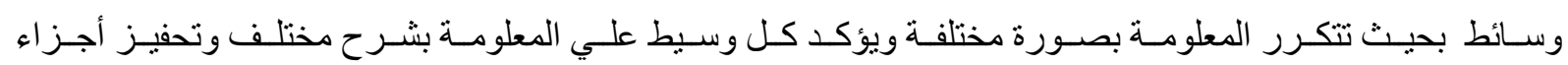

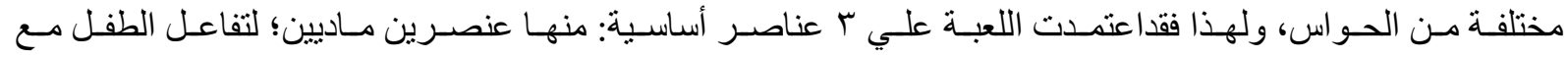

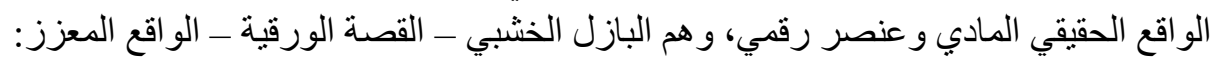

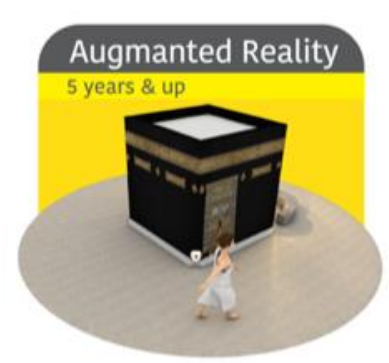

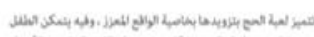

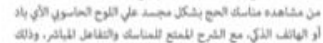

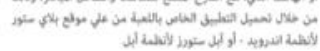

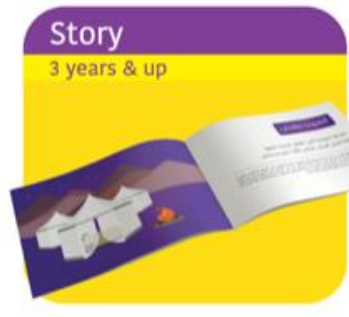

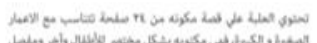

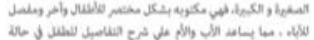
10

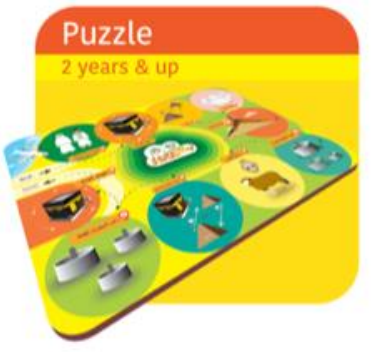

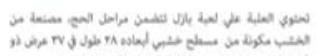
年

$$
\text { شكل (1 ) مكونات لعبة الحج }
$$

أو لا: البازل الخشبي(ب سنوات فما فوق) :

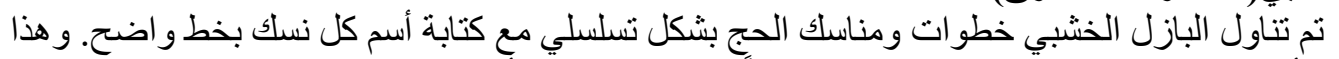

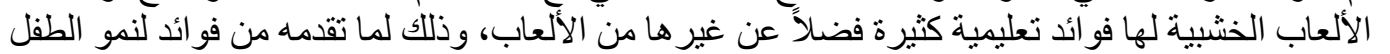

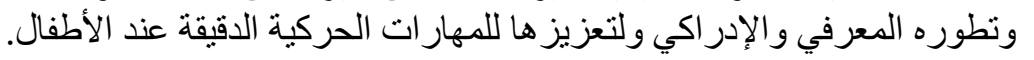
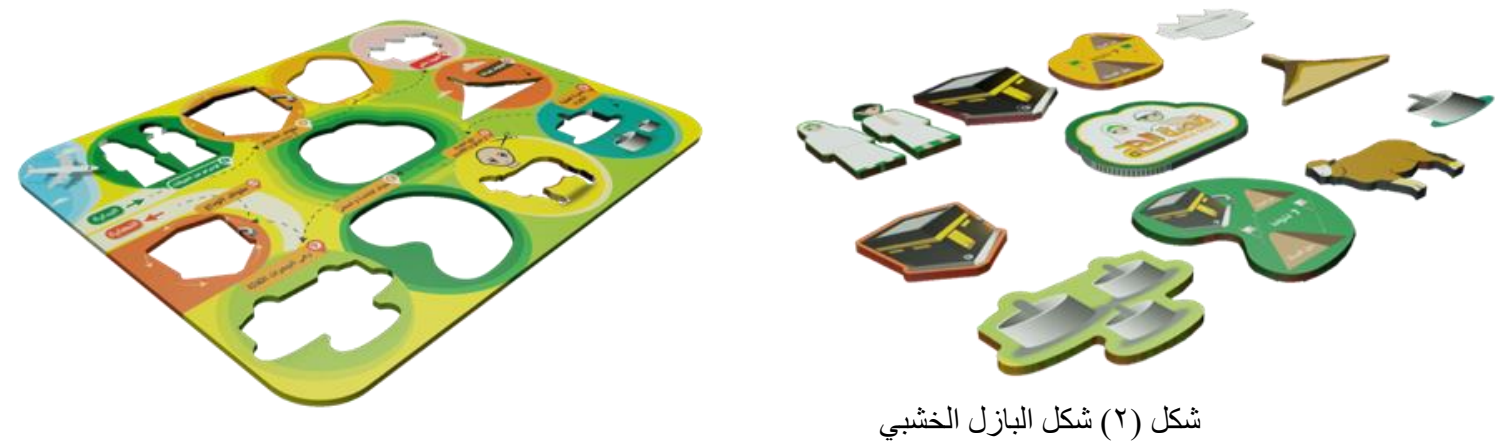

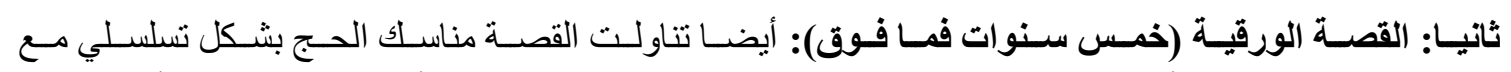

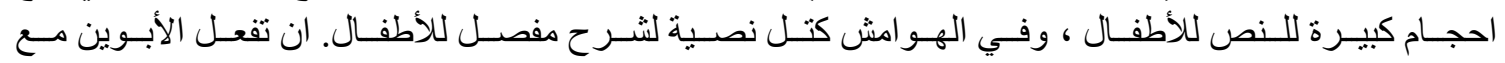

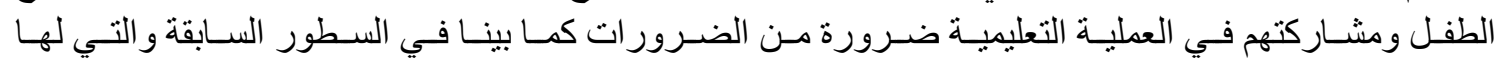
أثر نفسي علي الطفل وتحسين اداءه الإدر اكي. 

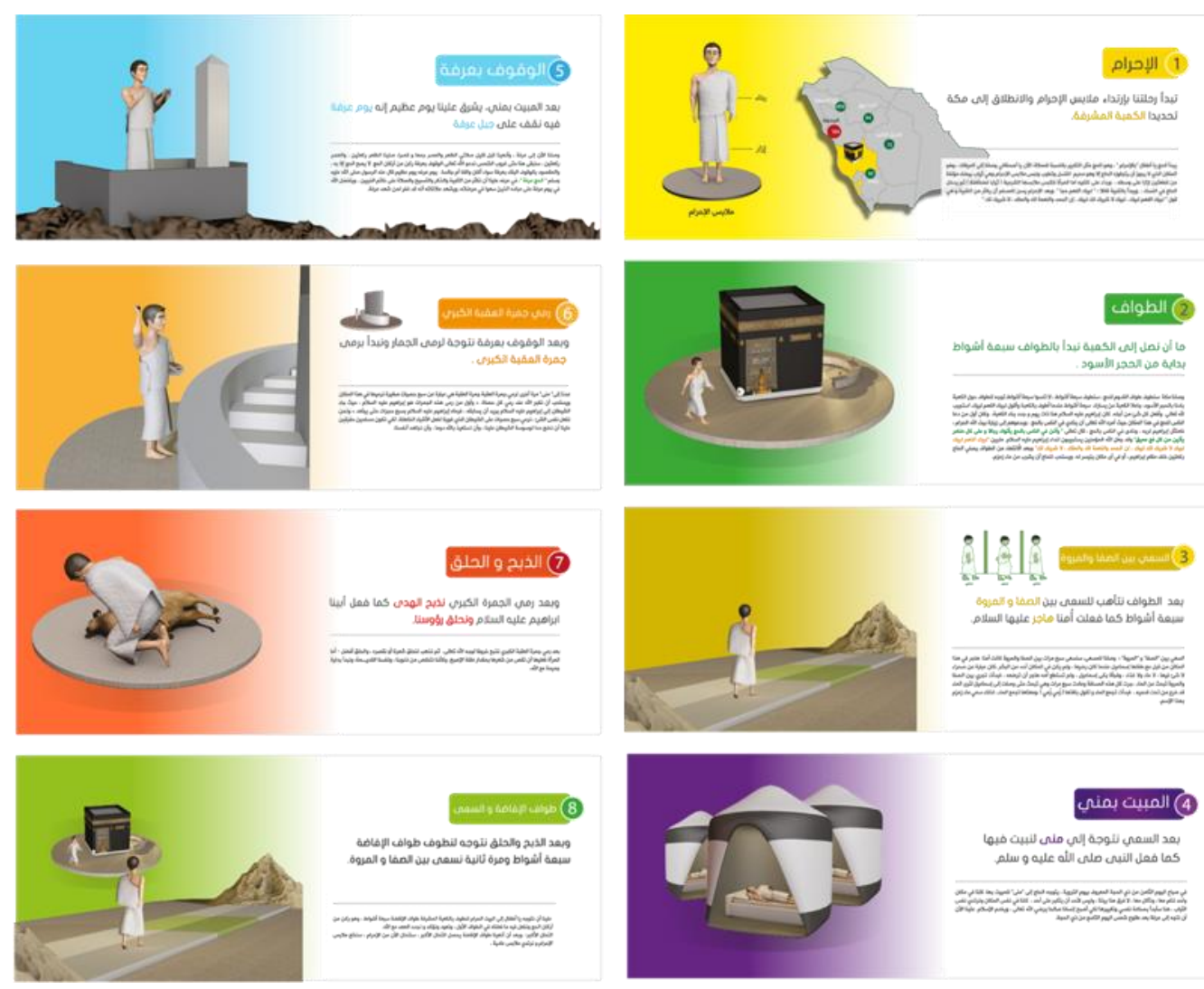

شكل (r) التنسيق الداخلي لقصة الحج

\section{ثالثا: قصة الحج بالواقع المعزز (سبع سنوات فما فوق):}

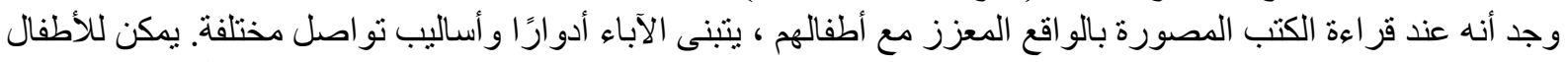

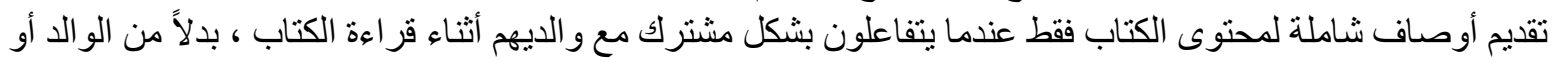

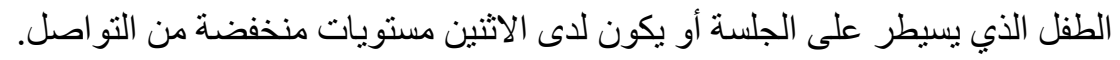
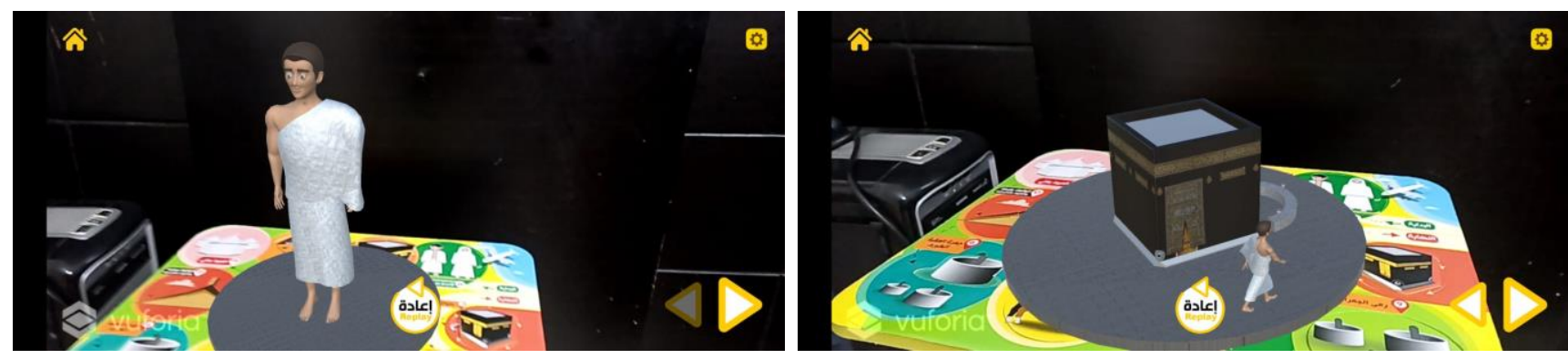

شكل (ء) لقطات من تطبيق الحج بتقنية الو اقع المعزز

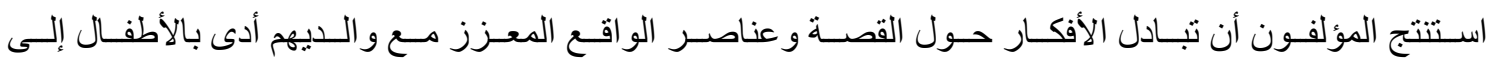

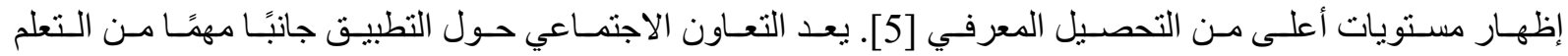

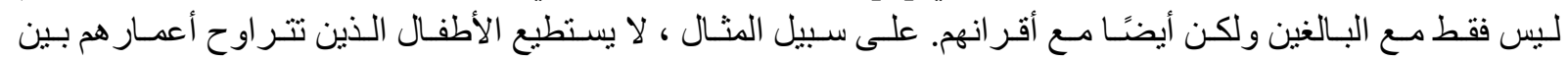

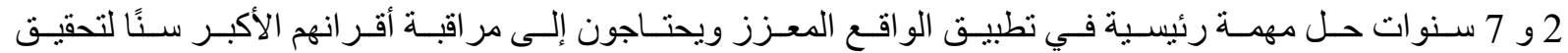

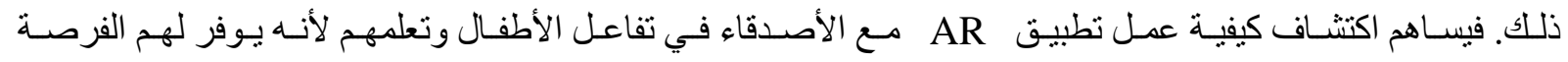




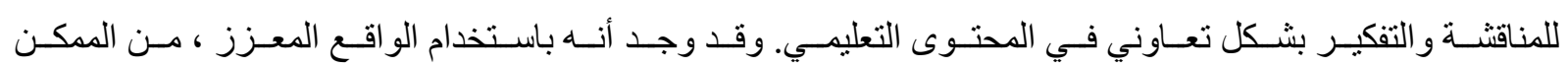

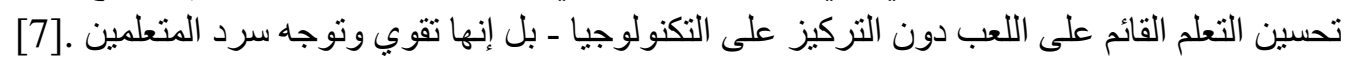

$$
\begin{aligned}
& \text { مراحل التصميم والتنفيذ }
\end{aligned}
$$

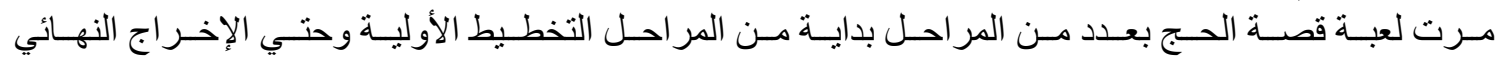

$$
\begin{aligned}
& \text { للمنتج. ويمكننا أن نوجز ها فيما يلي: } \\
& 1 \text { ـ المخططات الأولية: }
\end{aligned}
$$

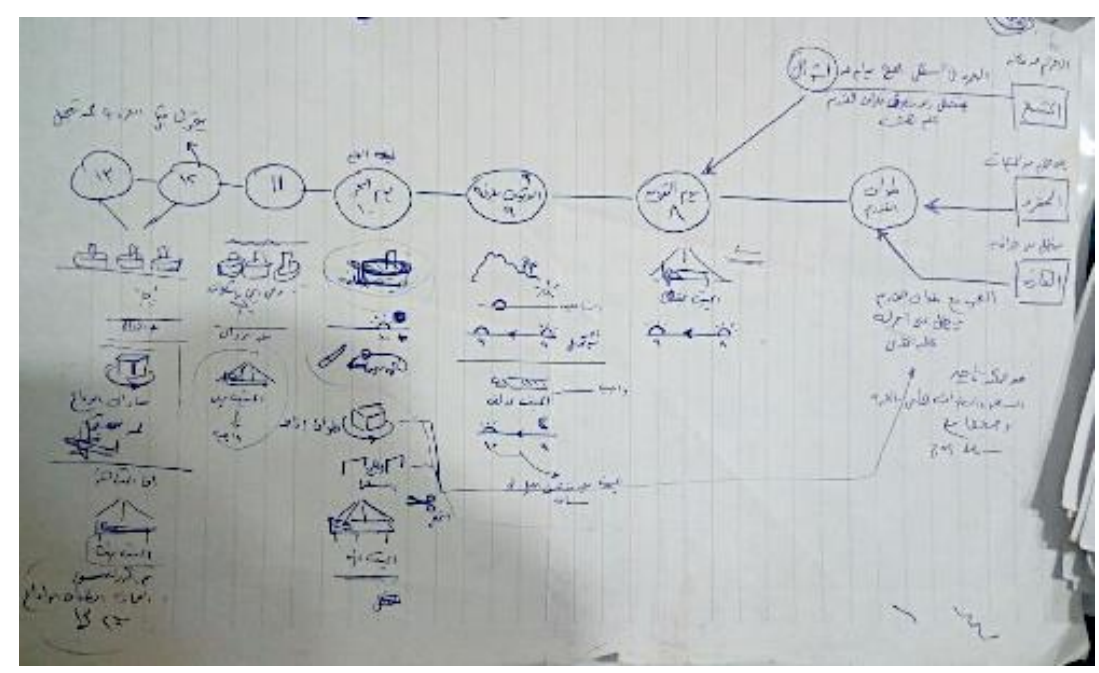

شكل (0) الرسم المبدئي لتخطيط لمر احل الحج 


\section{TECHNOLOGY}

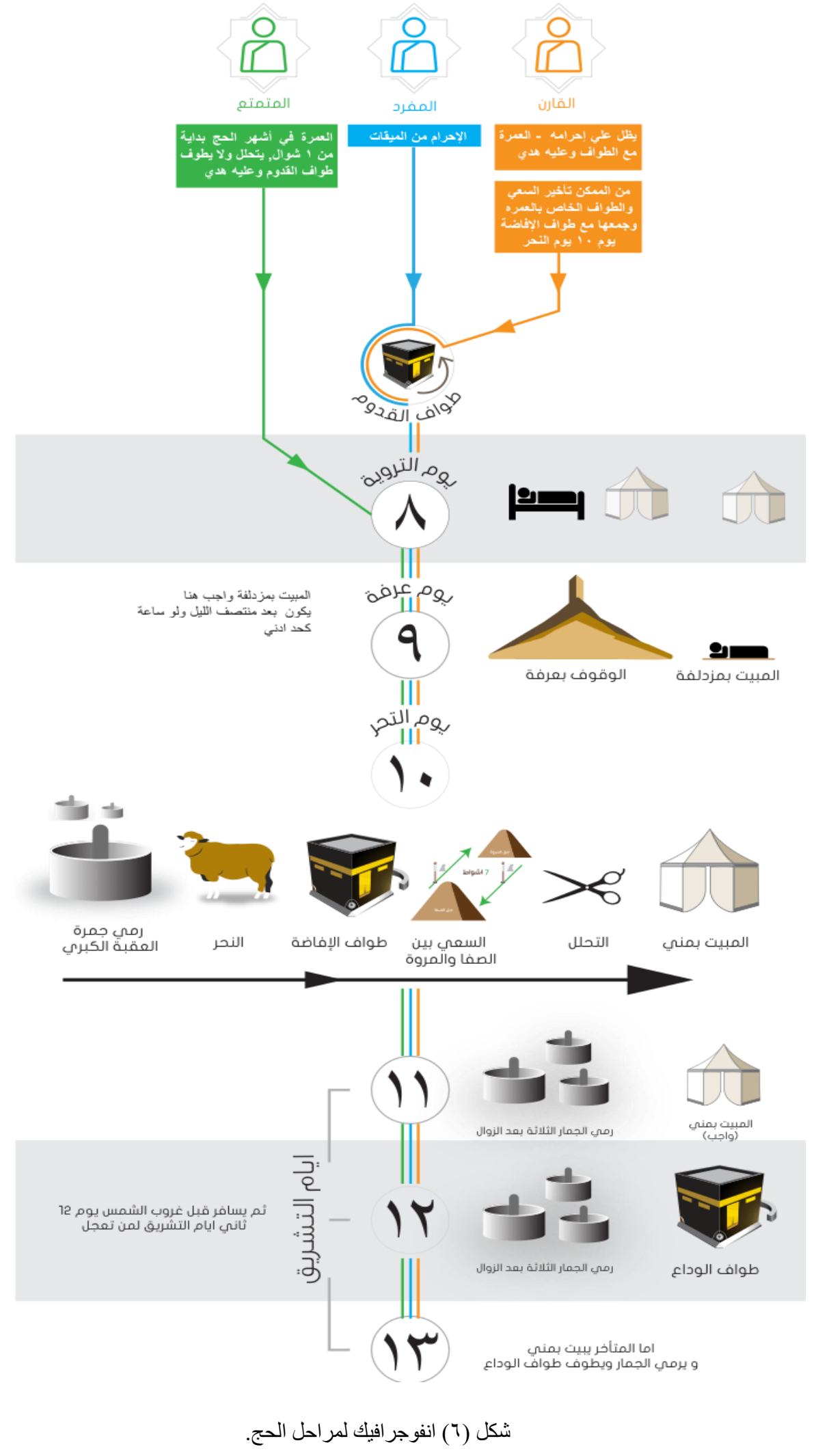




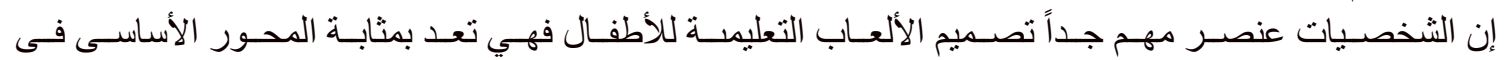

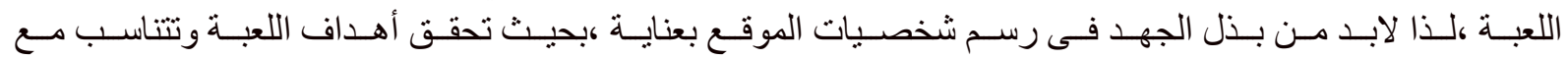

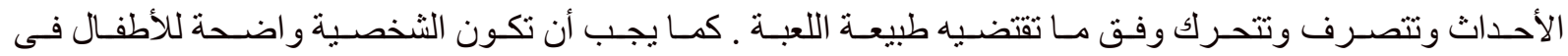

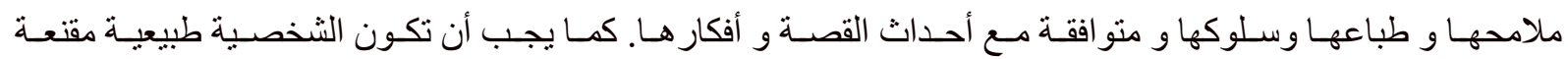

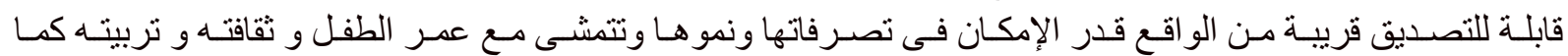
يجب أن لا تكون تصرفات الثخصية الو احدة متناقضة مع حقيقتها.

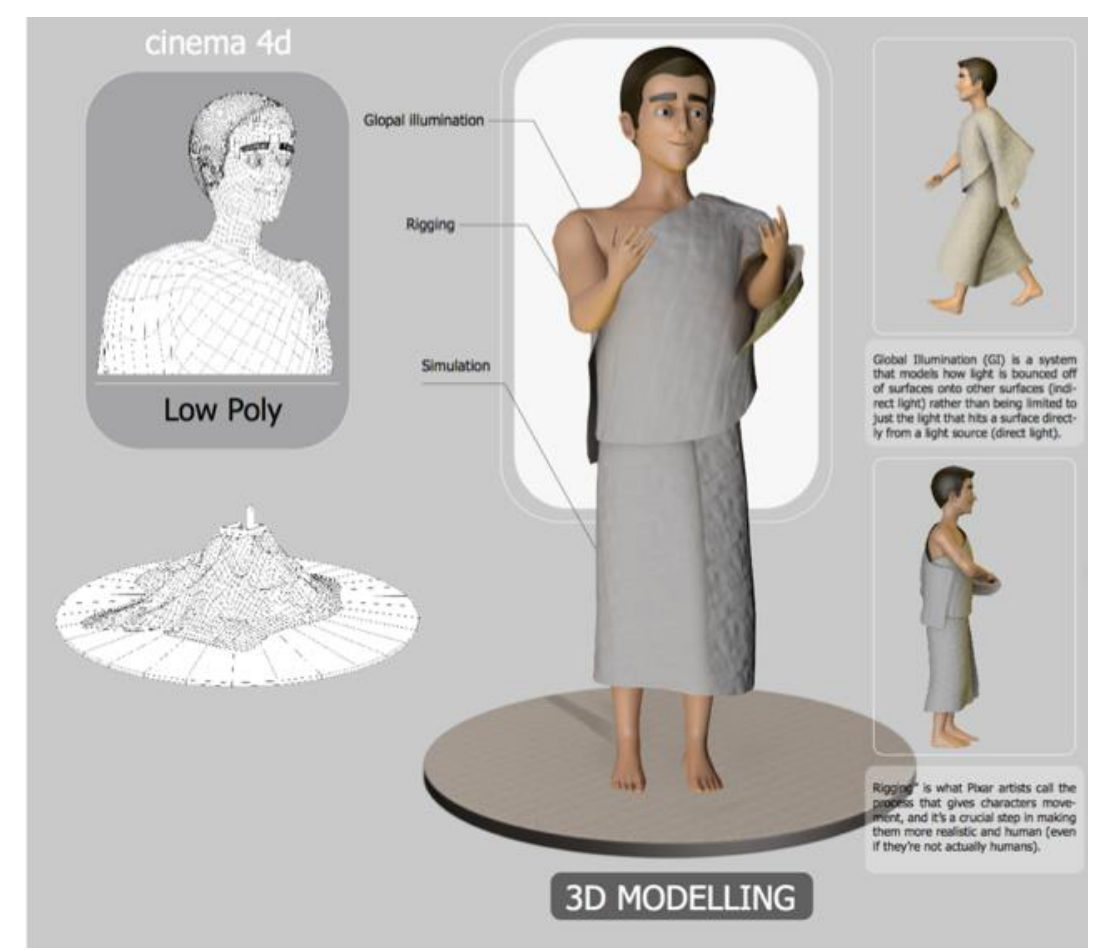

شكل (V) تصميم الشخصية الأساسية للعبة الحج

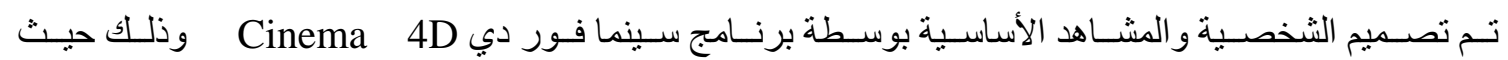
مرت تصميم الثخصية بعدة مرحل أهمها: مرحلة الرسوم الأولية

Polygons تم تنفيذ المضلعات و الكتل الأساسية ثم الملابس و الخامات ثم وضع الهيكل العظمي

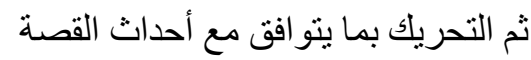

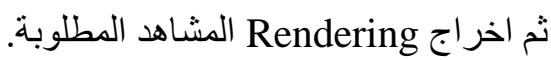

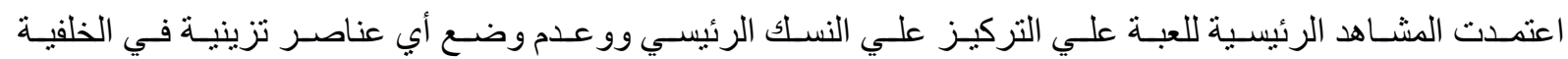

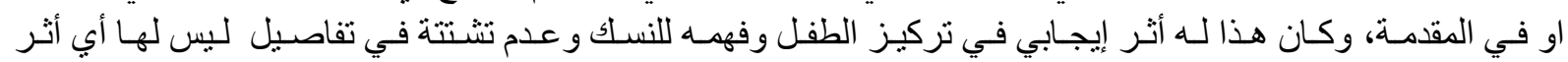
علي النسك و العبادات. 


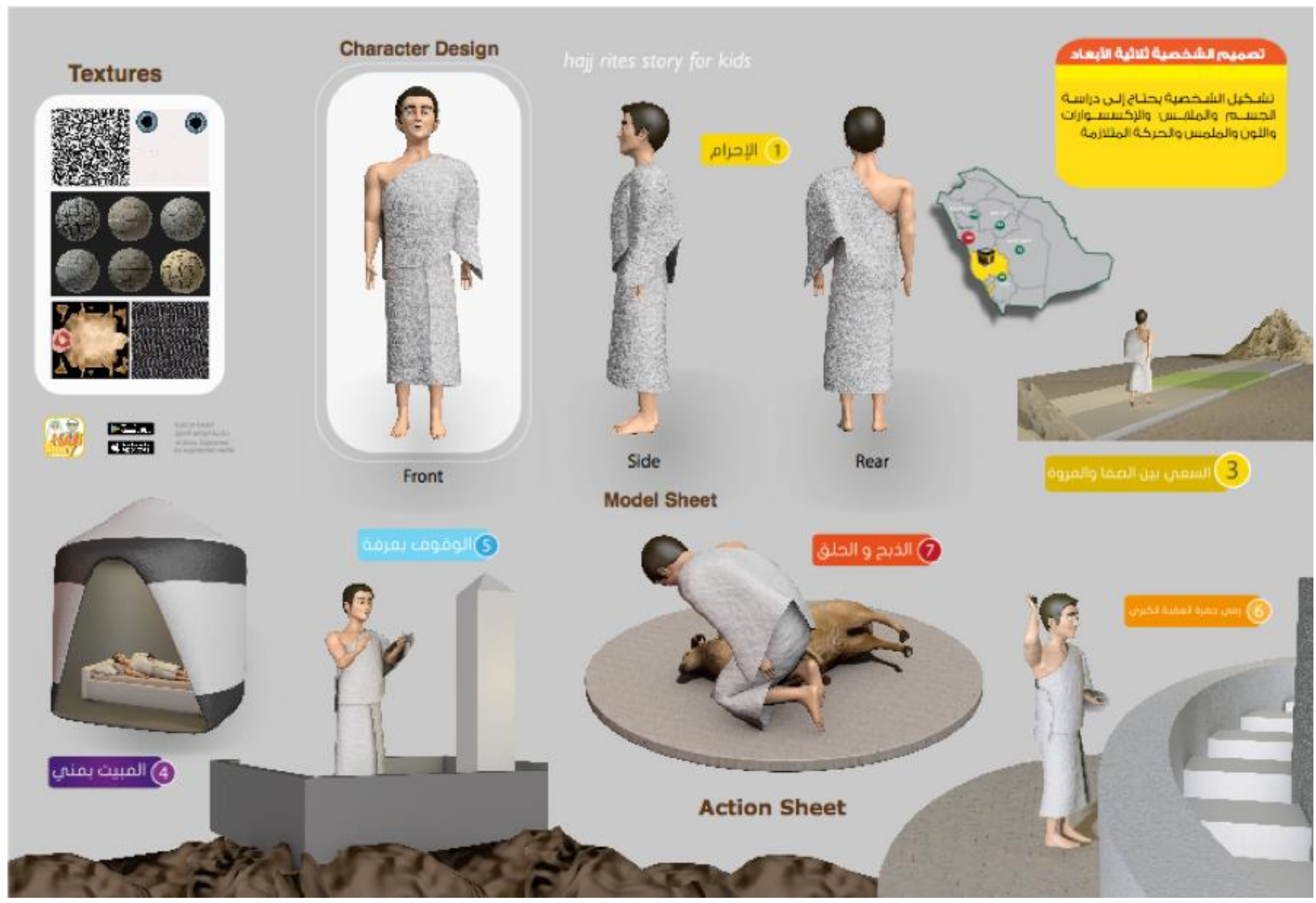

شكل (^) المشاهد الأساسية لقصة الحج.

3 - يكلة المعلومات:

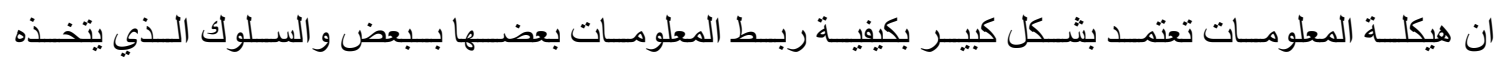
المستخدم للوصول اليها ولها عدة أنواع المعلومات نعاع علي الرغم من أن مصطلح 》هيكلة المعلوماتش) هو مصطلح حديث نسبيا ، إلا أنه في الحقيقة ممارسة قديمة [1] فدائما ما يبحث الناس عن طريقة تمكنهم من هيكلة معلو ماتهم بحيث يتمكن غير هم من فهمهاو واستعمالها.

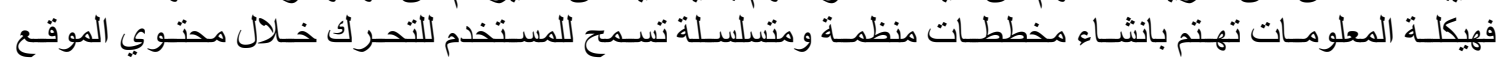

أو التطبيق بكفائة وسهولة.

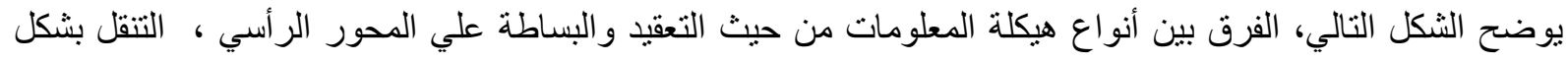

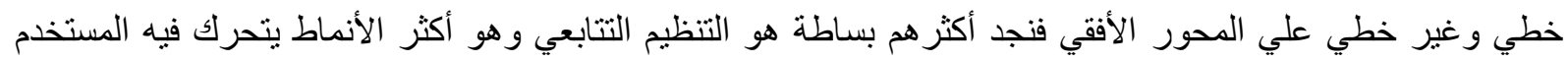
بشكل خطي بينما هيكلة المعلومات بشكل شبكي هو اكثر هم تعقيدا وبعدا عن الحركة الخطية. 


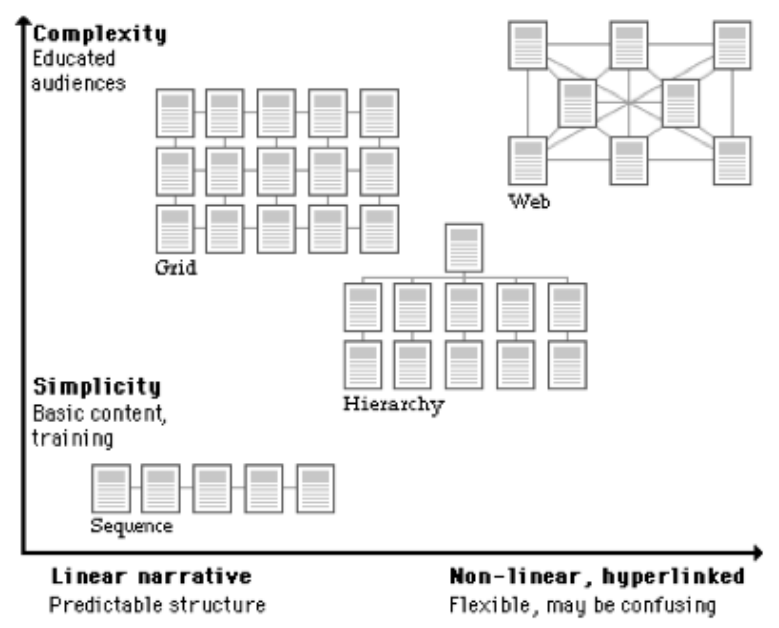

شكل (9) أنواع هيكلة المعلومات من حيث التعقيد علي المحور الرأسي، والتوزيع الخطي علي المحور الأفقي

ويعتبر الهيطلة الخطية Linear هو ابسط طرق هيكلة المعلومات وهو من خلال وضعها متتابعة (سلسلة متعاقبة) و هذا الترتيب التتابعي قد يكون وفقا للأحداث الزمنية ومتتابعه مثل مجموعة منطقية من الاحداث تتطور من العام الي الخاص او ترتيبا أبجديا كما هو ف الفهارس والقو واميس أو الموسوعات.

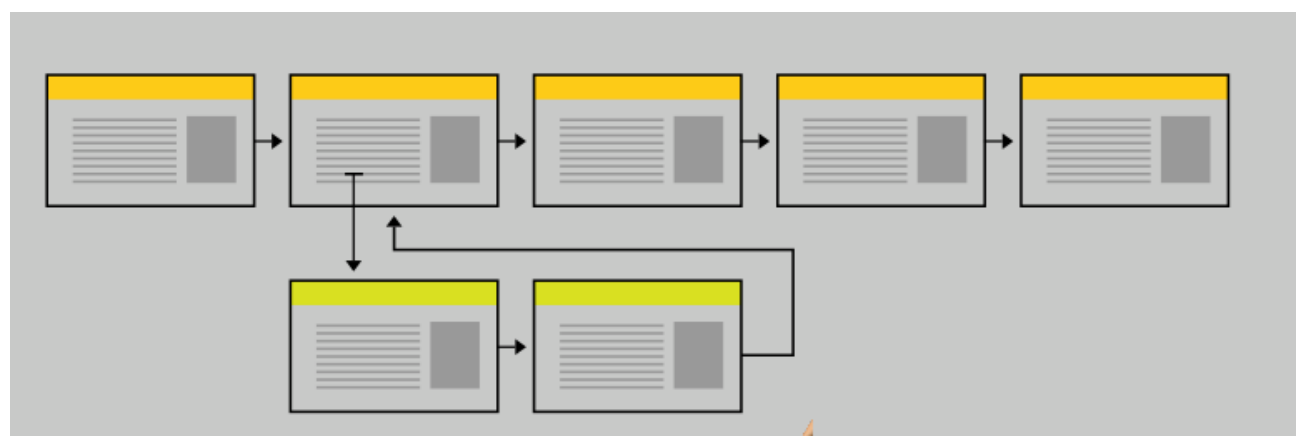

شكل (• ( ) هيكلة المعلومات النمط الخطي المستخد في قصة الحج

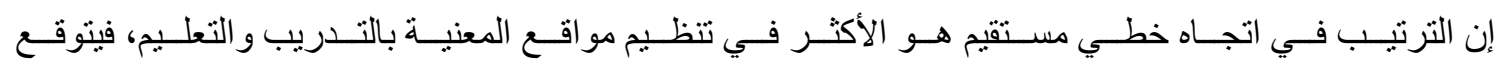

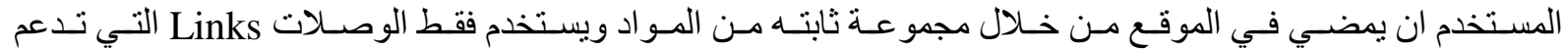
هذا الطريق. ايضا من الثائع في هيكلة المعلومات بشكل تتابعي أن يكون هناك بعض الصفحات الفر عية التي تسمح للمستخدم

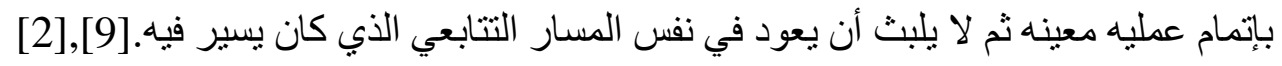




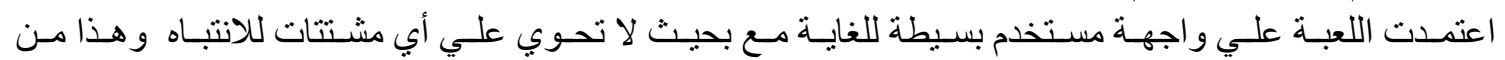

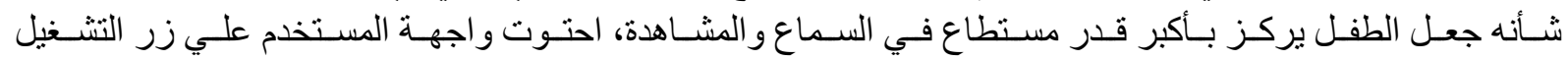

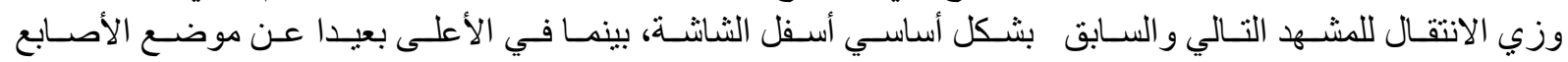

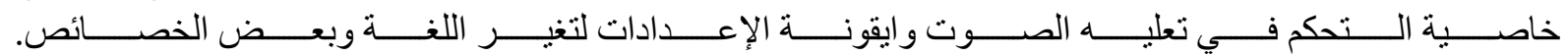

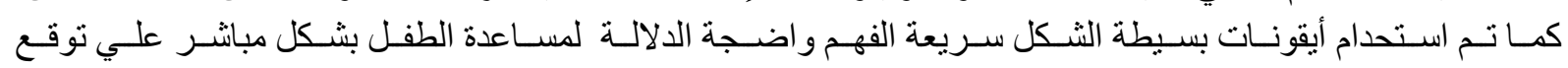
المطلوب.
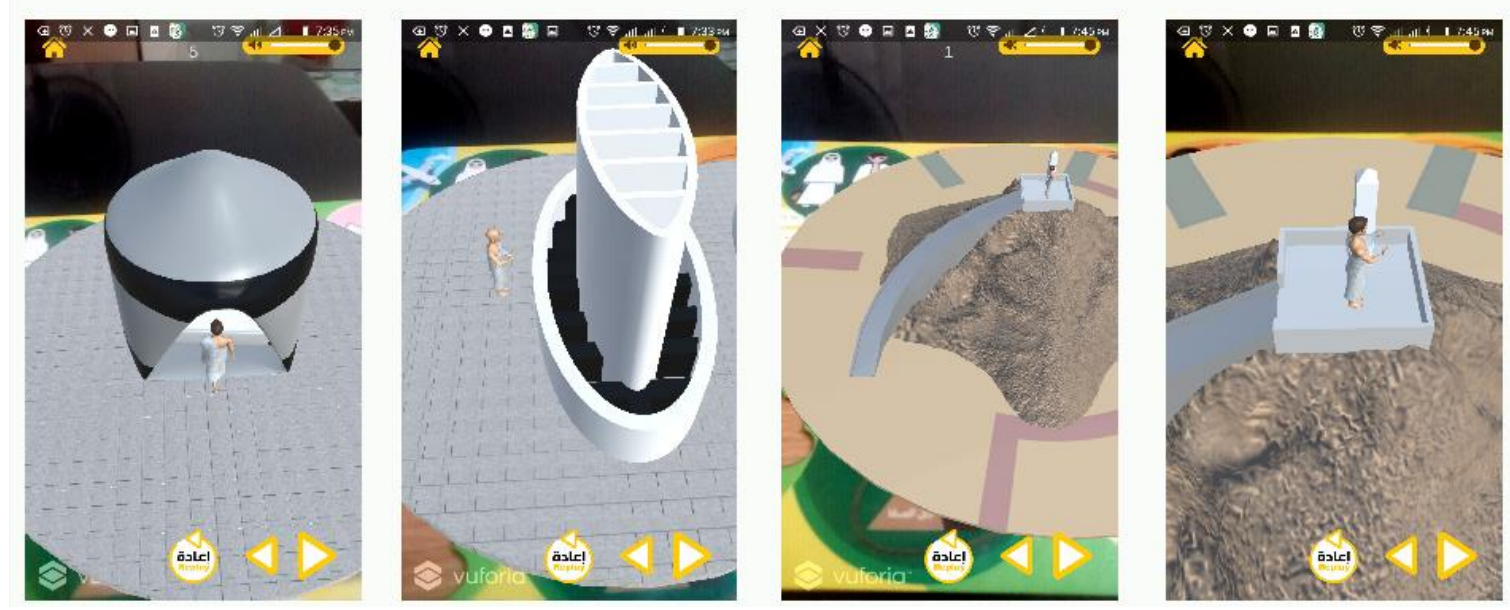

شكل (1 (1) لقطات من الثاثة ألو اقع المعزز لقصة الحج
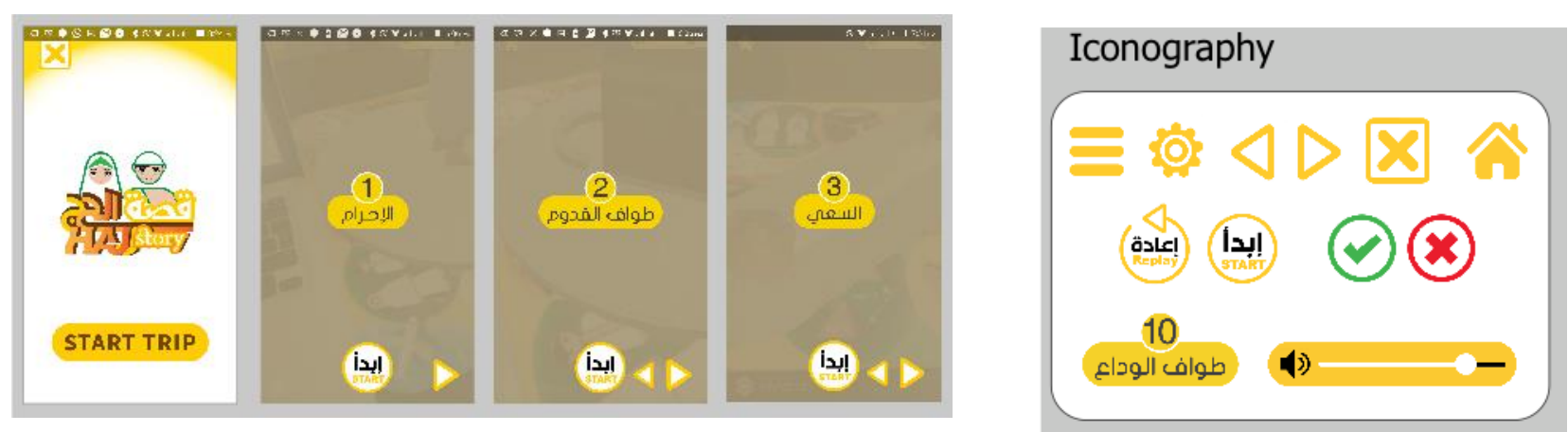

شكل (r ا ) الرسوم الأيقونية في شاشات اللعبة

5 - برمجة اللعبة:

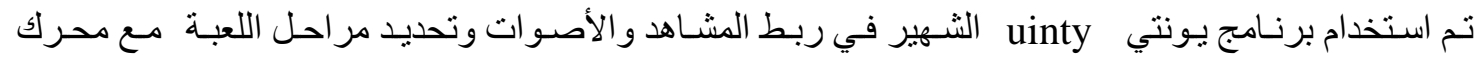

Vuforia

Unity

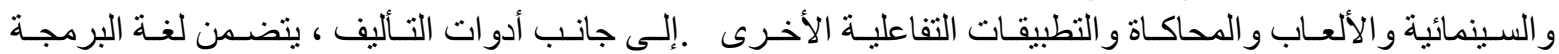

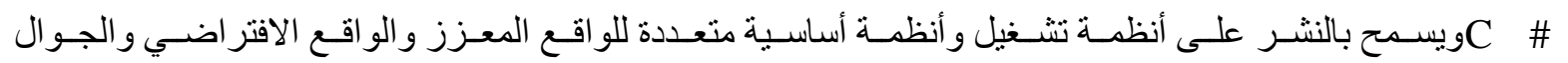

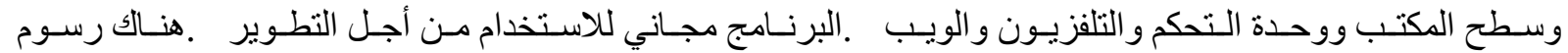
ترخيص للنطبيقات التجارية . 


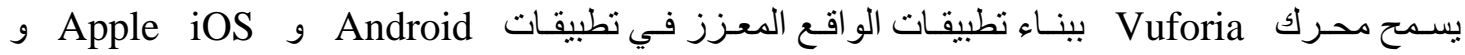

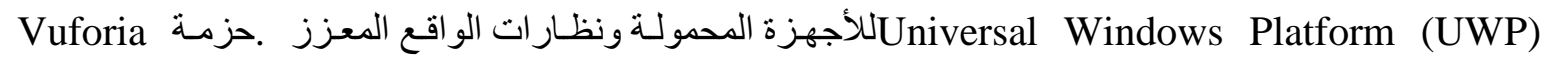

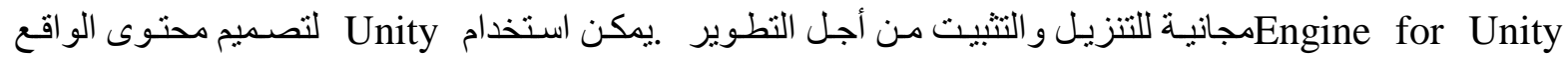

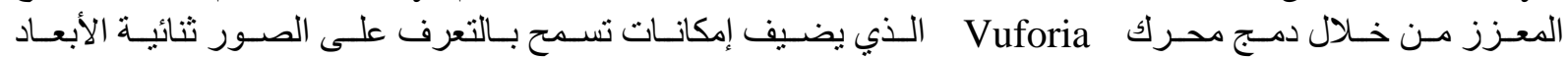

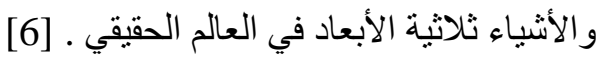

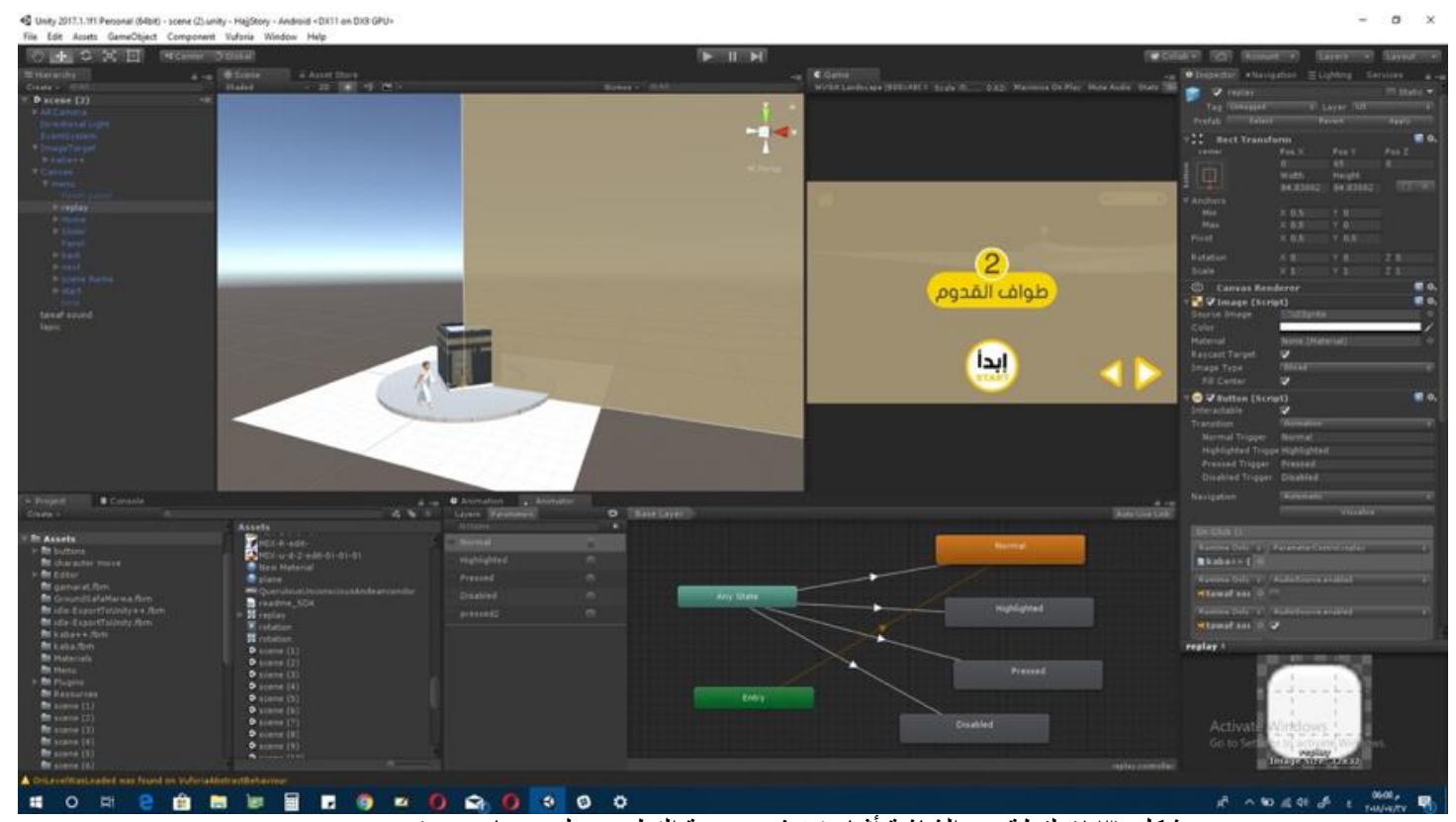

Unity شكل (r ا ) لقطة من الثاثة أثناء تنفيذ وبرمجة النطبيق علي برنامج

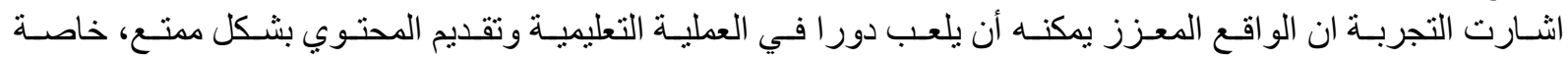

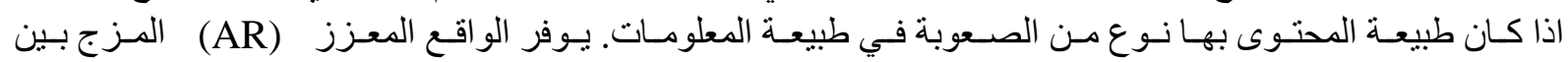

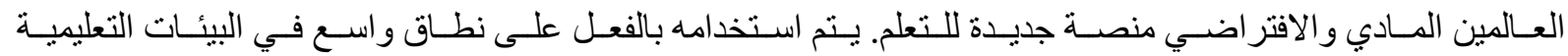

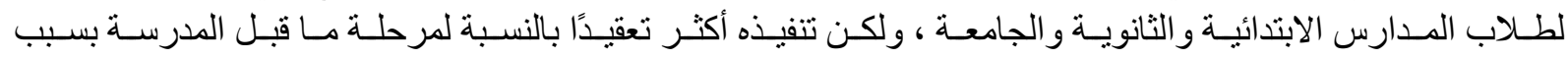

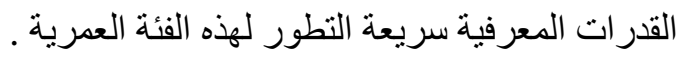

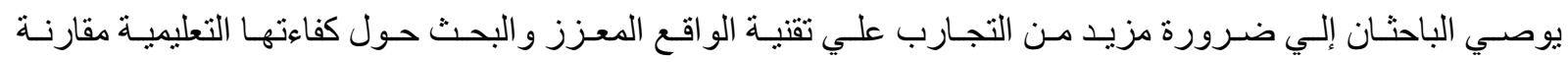
بالطرق التقليدية.

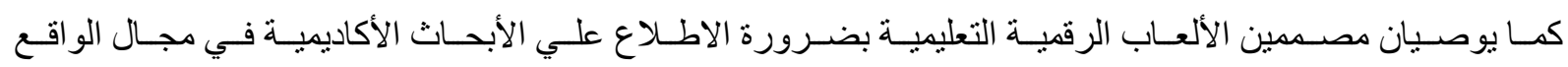

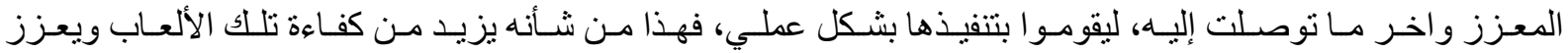
العرض التعليمي لها. 
[1] Garrett, Jesse James. The Elements of User Experience: User-Centered Design for the Web and Beyond. 2011

[2] Hassan, Ibrahim. The Graphical Experience Book for user centered design, Al amal pub., Alexandria, Egypt, 2019.

[3] J. Marsh, D. Plowman, D. Yamada-Rice, J.C. Bishop, J. Lahmar, F. Scott, A. Davenport, S. Davis, K. French, M. Piras, S. Thornhill, P. Robinson, P. Winter, Exploring Play and Creativity in Pre-Schoolers' use of Apps: Final Project Report, 2015, Retrieved from: http://www.techandplay.org/reports/TAP_Final_Report.pdf.

[4] K. Hirsh-Pasek, J.M. Zosh, R.M. Golinkoff, J.H. Gray, M.B. Robb, J. Kaufman, Putting education in educational apps: lessons from the science of learning, Psychol. Sci. Public Interes. 16 (2015) 3-34, http://dx.doi.org/10.1177/1529100615569721.

[5] K.H. Cheng, C.C. Tsai, Children and parents' reading of an augmented reality picture book: analyses of behavioral patterns and cognitive attainment, Comput. Educ. 72 (2014) 302-312, http://dx.doi.org/10.1016/j.compedu. 2013.12.003.

[6] Leighton, Fred. "Developing Mobile Augmented Reality with Unity and Vuforia." MW20: MW 2020. Published January 15, 2020. Consulted January 13, 2022. https://mw20.museweb.net/paper/developing-mobile-augmented-reality-with-unityand-vuforia/

[7] M. BodeÅLn, A. Dekker, S. Viller, B. Matthews, Augmenting play and learning in the primary classroom, in: Proc. 12th Int. Conf. Interact. Des. Child., 2013, pp. 228-236, http://dx.doi.org/10.1145/2485760.2485767.

[8] R.-R. Rasalingam, B. Muniandy, R.R. Rasalingam, Exploring the application of augmented reality technology in early childhood classroom in Malaysia, IOSR J. Res. Method Educ. 4 (2014) 33-40, http://dx.doi.org/10.9790/7388- 04543340.

[9] Rosenfeld, Louis, and Peter Morville. Information Architecture for the World Wide Web. Farnham: O'Reilly, 2007 